\title{
Doença, Política e Subjetividade no Ativismo Soropositivo no Estado do Paraná ${ }^{1}$
}

\section{Tiago Moreira dos Santos ${ }^{2}$}

\section{Resumo}

0 autor analisa os modos pelos quais um grupo de ativistas soropositivos dão sentido e conectam experiência da doença e política. 0 foco está no sentido e na interpretação elaborados pelo grupo, aí a emergência de um modelo nativo que congrega doença $e$ política sob a base de categorias comuns é visto como parte do processo de produção de uma subjetividade ativista e uma estratégia de deslocamento em relação à margem. A pesquisa deteve-se em grande parte na análise de narrativas, 0 ato de narrar encarado como momento em que experiências comuns puderam ser partilhadas e reelaboradas sob a perspectiva de um sujeito coletivo. Em um olhar desde as narrativas o ativismo éentendido como uma teoria sobre o mundo e como realidade vivida. Para o autor esta teoria erguida sob o patamar de categorias, são estas também que sustentam e dão sentido à experiência. É assim também que este modelo também leva a pensar dimensões como as da pessoa e da corporalidade e como elas são vividas a partir do ativismo.

Palavras-chave: Ativismo soropositivo, saúde/doença, política, narrativa, pessoa, corporalidade.

\section{Abstract}

The author analyses the ways by which a group of HIV+ activists make their experience meaningful and connect it to politics. The focus is on meaning and interpretation elaborated by the group; hence, the emergence of a native model that congregates disease and politics based on common categories is seen as part of an activist subjectivity production process and a dislocation strategy in relation to the margin. The research focused, to a great extent, on the narratives analysis - the narrative act considered as a moment when common experiences could be shared and re-

\footnotetext{
${ }^{1}$ Este artigo reproduz em parte uma comunicação apresentada no Fórum Políticas e Subjetividades nos "Novos Movimentos Culturais", na XXIV Reunião Brasileira de Antropologia - Olinda, 2004, sob o título "Da experiência da doença ao ativismo: Itinerário de pessoas vivendo com HIV/Aids".

${ }^{2}$ Professor da Universidade do Estado de Santa Catarina (Udesc) - Mestre pela Universidade Federal de Santa Catarina (UFSC) - e-mail: est_fragmento@yahoo.com
} 
elaborated under the perspective of a collective subject. Within a view of the narratives, activism is understood as a theory about the world and as an experienced reality. For the author, these theories are founded on categories, which sustain and attribute meaning to experiences. It is also in this way that this model understands dimensions belonging to the person and his/her embodiment and how they are experienced from an activist perspective.

Keywords: HIV+ Activism, health/disease, politics, narrative, person, embodiment.

\section{INTRODUÇão}

$\mathrm{E}$ m dezembro de 2002 fui convidado por membros da Associação Londrinense Interdisciplinar de Aids (ALIA) a auxiliar nas atividades da reunião de instauração da Rede Paranaense de Ativismo e Cidadania (REPACI). Já trabalhava há pelo menos há um ano desenvolvendo atividades como escrita e coordenação de projetos. a instauração da rede, era chamado a colaborar na sistematização de um roteiro de avaliação elaborado pelo grupo ${ }^{3}$. 0 que não sabia até então é que esta experiência seria o ponto inicial de um conjunto de reflexões sobre as relações estabelecidas no interior do movimento soropositivo entre doença e política. A participação neste encontro me colocava frente à questões interessantes sobre os modos como a relação doença/política é agenciada no interior do movimento soropositivo no estado do Paraná.

As inquietações vividas neste momento seriam o ponto de partida para a elaboração de uma pesquisa de mestrado em antropologia. Neste sentido, este artigo reflete as preocupações iniciais que deram fruto a minha dissertação de mestrado defendida em 2005 no Programa de Pós-Graduação em Antropologia Social da Universidade Federal de Santa Catarina (PPGAS-UFSC). Assim sendo, 0 artigo apresenta dados de campo e reflexões preliminares. A pesquisa de campo foi realizada durante os anos de 2003 e 2004, neste período pude conviver com grande parte das aproximadamente 100 pessoas que compunham a REPACI fazendo observações e colhendo narrativas.

No campo, desde o inicio, as narrativas biográficas apareciam como um elemento importante na recuperação dos sentidos em torno do sujeito "ativista", portanto, uma via privilegiada de acesso não somente à subjetividade mas também para o traçado entre a experiência da doença e o ativismo político. As biografias dos "ativistas" remetem à biografia de um sujeito coletivo (BOLTANSKI, 1982), e essa é uma referência constante nas narrativas. Tanto neste artigo, como em minha dissertação de mestrado, as narrativas

\footnotetext{
${ }^{3}$ Segundo o relatório técnico-narrativo do projeto, tal instrumento constituiria um roteiro de questões-chave que seriam usadas para discussão dos "princípios fundantes" da REPACI (Associação Londrinense Interdisciplinar de Aids, 2002).
} 
são tomadas como centrais na compreensão da experiência da doença e dos modelos interpretativos gerados pelo grupo (MALUF, 1999, p.73). Por outro lado é preciso destacar que elas não são os únicos veículos de sentido e não dispensam e pesquisa de campo no sentido mais tradicional do termo.

Devido a questões de espaço, a explanação dos resultados se detêm em uma análise que abstrai as falas concretas dos informantes encontrando-as em modelos antropológicos mais gerais sobre pessoa, doença e política. Isto é, aquilo que há de concreto nas narrativas e no trabalho de campo é abstraído em nome da construção de modelos de interpretação das categorias de pensamento nativas, sem que necessariamente estas se confundam com aquilo que os nativos dizem concretamente. 0 caso é que se tratam de conceitos que se referem à ordenamentos intelectuais mais do que à ordem empírica (LÉVI-STRAUSS, 1976). Claro que isso é feito sem perder de vista que a pretensão é desvendar uma lógica particular pela qual uma experiência de mundo se desenrola, no entanto, crê-se que as categorias, como tal, tem um papel fundamental na organização dessas (SEEGER, DA MATTA; VIVEIROS DE CASTRO, 1979, p.15). Assim, o presente artigo procura recobrir um campo de análise demarcado pela noção de categoria remetendo-se a estas como nível importante na constituição do sentido.

Um dos primeiros desafios é entender os sentidos que a doença recobre. Os estudos antropológicos sobre o processo da doença têm mostrado o quanto as experiências de adoecimento passam pelo crivo das representações sociais. A doença, enquanto acontecimento, é uma erupção contra o fluxo da vida cotidiana, um momento de desordem, exigindo mobilização e interpretação sociais (AUGÉ, 1991). AAids, sob vários aspectos, é um exemplo privilegiado desse processo onde os sentidos que envolvem a experiência e a interpretação da doença são negociados. Movimentando um complexo jogo de negociações e conflitos, seus sentidos emergem dos embates entre a política científica e os movimentos sociais (BASTOS, 2002). Neste sentido, este artigo procura também apontar algumas das interconexões existentes entre experiência da doença, seus modelos de interpretação, e a produção de uma experiência política singular no interior do ativismo soropositivo no estado do Paraná.

A literatura sobre antropologia da doença, assim como aquela que trás contribuições para a história das epidemias tem apontado para a produção de representações da doença como um mal ancorado no Outro, situado tanto como uma referência ao estrangeiro, como ligada a grupos estigmatizados do interior da própria sociedade (JEOLÁS, 1999). Na mídia eram comuns as associações à comunidade gay e referências como "doença de homossexuais" e "peste gay". Esse fato parece ter sido 
reforçado por uma identificação dos primeiros casos entre indivíduos pertencentes à comunidade gay em países como os Estados Unidos. No Brasil, o início da epidemia também foi marcado por este tipo de identificação, reforçando estigmas e práticas de discriminação.

Como assinalam Herzlich e Pierret (2005), quando suscita um imaginário de mal diruptivo de toda a sociedade, a epidemia da Aids articula de modo singular as dimensões biológica, social e política de modo que é possível perceber as imagens que emanam dessa articulação reproduzidas em diversos contextos, assim como no próprio discurso científico. Neste sentido, os saberes biomédicos, através de conceitos como o de "grupos de risco" proposto pela epidemiologia, corroboraram para reforçar estigmas e representações negativas a respeito da doença, homogeneizando práticas e comportamentos de grupos e indivíduos (GALVÃo, 2000; PARKER, 1994; POLLAK, 1990).

A Aids como objeto de uma grande mobilização social trouxe desafios para a área científica e para os movimentos sociais (BASTOS, 2002), as implicações políticas não estavam dadas somente no que diz respeito ao imaginário da doença. A epidemia coincide com um período de intensas mudanças na política do século XX, e o contexto que emerge entre as décadas de 60 e 80, marcara profundamente o modo como as respostas políticas ao avanço da epidemia iriam se articular. Neste período vê-se a eclosão e a articulação de movimentos sociais de um novo tipo. Acompanhando a desterritorialização do capital, a perda da centralidade do mundo do trabalho e a derrubada das conquistas do chamado Estado do bem-estar-social, há o surgimento de movimentos que colocam em pauta a problemática dos chamados direitos nãouniversálizaveis, suas reivindicações pautadas em identidades étnicas e de gênero. Este processo não representa somente desagregação econômica e surgimento de novas pautas políticas, mas também é marcado pela ascensão do domínio da informação e dos meios de comunicação enquanto valores fundamentais para o capital e também a nova base através da qual esses movimentos sociais nascentes se consolidariam (ALVAREZ; DAGNINO; ESCOBAR, 2000, p.45).

Este processo interconecta o mundo e com as redes que cria subverte fronteiras tradicionais estabelecidas entre o global e o local (RIBEIR0, 1996). Realçando os contrastes e contradições deste mundo e permeado por múltiplas narrativas ${ }^{4}$, o HIV/ Aids, suas representações e os movimentos de resposta à epidemia correram pelas dinâmicas do mundo contemporâneo ajudando a desenhar a realidade social tal como

\footnotetext{
${ }^{4}$ Multivocal e em camadas sobrepostas, interferentes, concorrentes, impossível de limitar a uma narrativa unificada e única, a história das respostas à SIDA é um encadeamento de significados múltiplos presos a um referente comum que é também um facto novo - de saúde, de vida, de sofrimento (BASTOS, 2002, p.23).
} 
vivemos hoje. 0 ativismo global e a ação local passaram a encenar parte de uma história onde ainda figuram organismos financeiros (Banco Mundial) e de ajuda internacional.

No Brasil, o primeiro cenário é o de uma realidade política dura, marcada por uma ditadura militar, iniciada em princípio dos 60 e perdurando até 0 início da década de 80 quando de seu desfecho vê-se a ebulição de um otimismo político e a abertura para que novos movimentos possam se fortalecer na luta pela cidadania e pelos direitos civis. Já no fim da década de 80 o Brasil, como os demais países da América Latina, assiste a uma proliferação de diversos tipos organizações. Logo, como lembra Bastos (2002, p.117),

a resposta social à Aids no Brasil coincidiu com o período de expansão e consolidação das ONGs. No fim dos anos 80, a sigla ONG ocupara já a posição simbólica antes detida pelos movimentos, associações e grupos, tanto no campo da Aids como noutras esferas de intervenção social.

Sob a bandeira do combate à epidemia, se entrecruzaram atores diversos: universitários, igrejas, partidos de esquerda e militantes dos movimentos de autonomia sexual. Juntos, tinham à frente a luta pela "cidadania" como bandeira mais abrangente para a luta contra a Aids. Em outros países, como os Estados Unidos, por exemplo, os movimentos antiaids seguiram a inspiração do movimento gay, fortemente articulado no desde 0 início da epidemia. No Brasil, apesar de encontrarmos uma composição majoritariamente gay dos quadros do movimento, o modelo de organização seguiu mais as diretrizes sugeridas pelas agências internacionais de apoio ao desenvolvimento, figurando uma combinação entre os modelos da Organização Mundial da Saúde (OMS) e manifestações locais de ativismo social por direitos humanos, herdadas da luta contra a ditadura militar (BASTOS, 2002; GALVÃ0, 2000).

Entre 1989 e 1994, o movimento de ONGs/Aids encontrou o auge de sua ebulição. As comunidades afetadas assumiam a luta pelos seus direitos, exigindo que o problema da saúde fosse pensado a partir de uma perspectiva mais ampla, incluindo o enfrentamento de problemas como a pobreza, o desenvolvimento social e os direitos humanos. Na perspectiva desse movimento estava um maior envolvimento das pessoas vivendo com HIV/Aids. Assim, a partir da década de 90 , começa a surgir uma identidade soropositiva, tendência crescente com a formação, não só de organizações e de redes de pessoas vivendo com HIV/Aids, mas também de trazer à tona questões ligadas à pessoa soropositiva, sua inserção no movimento e sua visibilidade, assinalando os diferentes momentos da constituição dessa soropositividade como um discurso articulado frente à Aids.

A solidariedade, se construía como ponto articulador do movimento e postulava 
a necessidade de um ativismo político na reivindicação de políticas públicas (GALVÃO, 1994; POLLAK, 1990). Desde o início, portanto, uma gramática política foi fundamental na emergência dos movimentos de apoio e combate à Aids que apostavam em estratégias de empoderamento das pessoas vivendo com o vírus. Estas estratégias nunca deixaram de ter um caráter híbrido, em vários momentos se constituíam a partir de elementos próprios aos novos movimentos sociais, já em outros estavam entrelaçadas com diretrizes de organismos internacionais e políticas governamentais.

0 certo é que essas estratégias de empoderamento dos sujeitos se tornou uma diretriz fundamental dos programas governamentais, ajudando a costurar uma complexa rede que se formou entre as diversas respostas à Aids. Este movimento, que perpassa fronteiras e formado de estratégias múltiplas, encontrou forças nas redes formadas sem contrapartida geográfica e apoiadas na velocidade crescente que atinge os meios de comunicação. Embora a translocalidade possa ser uma característica marcante dos movimentos antiaids, é no plano local, que se pode perceber com maior clareza as ambigüidades geradas pelas políticas de financiamento e as transformações que são operadas na fabricação de um sujeito singular, mais ao mesmo tempo interconectado a uma rede discursiva e de conhecimentos sobre a epidemia.

\section{A Caminho de Uma “Delimitação” do Grupo}

Ao lado de uma afirmação das pessoas vivendo com HIV/Aids e da reivindicação dos rumos do movimento por essas pessoas, o Estado brasileiro procurou criar condições, através de financiamentos e treinamentos, para o fomento de lideranças soropositivas. 0 projeto da Coordenação Nacional de DST e Aids (CN DST e AIDS/MS) "Liderança e Ativismo", criado em 1998, tinha esse objetivo. Rio de Janeiro e São Paulo já possuindo pessoas vivendo com Aids como fortes lideranças políticas no movimento, o objetivo era desenvolver habilidades de ativismo e liderança em outras regiões, sobretudo no interior. 0 primeiro piloto deste projeto foi realizado na região sul, vindo a concretizar a participação do governo em iniciativas deste tipo e consolidando também a idéia sustentada por vários movimentos e pelo Banco Mundia//UNESCO de que os programas têm maior êxito quando envolvem as pessoas atingidas pela epidemia.

Postulando que as pessoas vivendo com HIV/Aids deveriam deixar de ser parte do problema para ser parte de sua solução, o projeto da Coordenação Nacional de DST e Aids buscava a multiplicação dos treinamentos e a geração de novas iniciativas. 0 projeto "Ativismo e Cidadania", iniciado em 2000, visava promover este ideal no estado Paraná. 
A história deste projeto começa no momento em que dois membros ${ }^{5}$ ALIA, voltam dos treinamentos do piloto da Região Sul. Convencidos de uma grande mudança, a vontade era dar continuidade, reproduzir aquilo que tinham experienciado nos treinamentos. Uma das ativistas que entrevistei assinala este fato da seguinte maneira:

Lá comigo aconteceu assim: a descoberta dos direitos, que não era tão simples só, "saúde dever do Estado direito do cidadão". Foram doze dias que mudaram minha vida muito, da volta para cá. Então de lá para cá, a vontade era reproduzir aquilo [...]. (Ativista)

A proposta era, como no projeto anterior, instrumentalizar pessoas que vivem com HIV/Aids estimulando-as na busca de seus direitos de cidadania e no controle social das políticas públicas de saúde (Associação Londrinense Interdisciplinar de Aids, 2002). Contudo, esses treinamentos têm um desdobramento fundamental na reelaboração dos modelos de explicação da doença. Elaborados principalmente a partir de dinâmicas de grupo, o fundamental é narrar a história de vida. As narrativas neste sentido, tiveram um papel fundamental no processo de reelaboração das histórias de vida, figurando como elemento central na conexão entre doença e política.

Durante os dois anos de existência do projeto, em torno de 100 pessoas já haviam passado pelos treinamentos. Ao final foi proposto o estabelecimento de uma organização em rede, a Rede Paranaense de Ativismo e Cidadania (REPACI). A proposta era a de articular pessoas participando de projetos, desenvolvendo ações individuais e em parceria com ONGs e Estado. No entanto, muito mais do que articular pessoas vivendo com vírus em torno da luta por políticas públicas, a rede emerge, em um contexto póstreinamentos, como um espaço de socialidade ${ }^{6}$ fundamental, um meio relacional de emergência de um sujeito singular (SANTOS, 2005).

Os treinamentos propiciaram momentos em que experiências comuns pudessem ser partilhadas e reelaboradas sob a perspectiva de um sujeito coletivo nas narrativas. Este fato foi observado no contexto de diversas pesquisas, como nas narrativas sobre culturas terapêuticas alternativas analisadas por Maluf (1996), onde a autora demonstra a presença de um sujeito coletivo que perpassa a construção do discurso narrativo. Os

\footnotetext{
${ }^{5}$ A formação deste projeto se deu a partir do treinamento de dois voluntários da ALIA no treinamento do projeto "Liderança e Ativismo", em fevereiro de 1998 na cidade de Florianópolis, promovido pelo Ministério da Saúde/ CN-DST/Aids (Coordenação Nacional de DST/Aids, hoje Programa Nacional de DST/Aids), como parte de suas estratégias de empoderamento da sociedade civil e formação de redes para o combate à Aids. 0 lema desse encontro era "Para que as pessoas infectadas deixem de ser vítimas ou parte do problema e se tornem parte da solução!", postulado neste momento pela socióloga norte-americana Ruth Gunn Mota.

${ }^{6}$ Sobre o conceito de socialidade pode-se consultar Strathern $(1988,1996)$, também Mccallum (1998) e Viveiros de Castro (2002).
} 
vínculos que formam a teia da REPACI são compostos de experiências e dramas sobre 0 HIV. Nesses dramas e experiências há mais em comum do que bistórias positivas. Os treinamentos deram lugar a outras conexões, os diferentes laços entre os pontos dessa rede se reforçam quando os ativistas se encontram em seus espaços de reuniões, como conselhos e fóruns de ONGs e da sociedade civil. Mas se foram momentos em que os ativistas compartilham experiências e subjetividades, pode se afirmar também que se tornaram espaços onde exercitam suas diferenças e sua segmentaridade política. Se diante do ativismo soropositivo no estado do Paraná se está diante de um sujeito coletivo, este fato não implica em uma homogeneidade que estaria acima dos sujeitos individuais. É preciso entender antes de tudo que o ativismo soropositivo é um modo de relação que se estabelece entre essas pessoas.

Por meio das viagens de campo, de encontros individuais com meus interlocutores e a participação em suas reuniões, pude perceber um universo fluído, marcado pela diversidade. Notadamente, o etnônimo essencial para se delimitar o grupo (soropositivo-ativista) ganha mais inteligibilidade externamente e em um olhar de pesquisador à procura de uma comunidade definida e homogênea. Mas em meio a diversidade que permeia um movimento tão fluído como este, o contexto da doença, do mundo social da Aids, coloca uma experiência comum ligada a um saber ser ativista compartilhado pelo histórico da experiência da doença, onde esses diversos aspectos podem ser relacionados por categorias comuns, mas que não reduzem o sujeito a uma identidade única. Foi nas narrativas, em um primeiro momento, que me dei conta de algumas categorias comuns que estruturavam e davam algum tipo de unidade ao discurso dos ativistas (SANTOS, 2005).

Quando a rede de relações que forma o movimento se concretiza em seus fóruns e reuniões locais, podemos encontrar um conjunto de relações de oposição e de complementaridade, emergindo como espaços de agenciamento de identidades e subjetividades e como um campo de disputas. A exemplo dessas oposições e complementaridades, também estão marcados os diversos encontros nacionais de ONGS/ Aids, marcados pelo clima de brigas e disputas, como narra Galvão (2000), resposta, segundo a autora, para a explicação do fracasso de diferentes projetos e iniciativas de articular o movimento nacionalmente.

De diferentes formas, a segmentaridade ${ }^{7}$ observada em vários momentos de

\footnotetext{
7 Quando falo em segmentação refiro-me a este conceito tal como utilizado por Evans-Pritchard (1978) para descrever a política na sociedade Nuer. Assim, entendo que a segmentaridade é, como sugere Herzfeld (apud GOLDMAN, 2001, p.75), um aspecto universal da vida política, representando um dos modelos de "relatividade social". No "ativismo", representa o arranjo das alianças políticas principalmente em relação ao foco das políticas de financiamento e as diferentes subjetividades presentes no interior do movimento.
} 
minha pesquisa de campo está relacionada, além da sua diversidade interna, às ambigüidades do relacionamento deste movimento com o Estado. Contudo, foi possível observar um conjunto de diferenças que dão margem ao conflito, no entanto, estas diferenças não se realizam dependendo do nível em que se encontram as oposições. Por exemplo, há uma relação conflitante entre identidades do movimento contra a Aids, como ex-usuários de drogas (redução de danos), gays, travestis e transgêneros, apesar de serem sessões do mesmo movimento, tais identidades podem, muitas vezes, estar em oposição. Porém, dentro de um espectro de relações entre ONGs, o conflito não se dá mais entre os grupos, mas entre as instituições. E numa outra esfera, as relações de conflito mostram uma unidade entre diferentes instituições e se direciona ao Estado.

Havia uma fluidez que atravessava o plano das estruturas do movimento e que encontrava, na práxis dos "ativistas", um terreno fértil para o desenvolvimento de segmentaridades. Quando se trata das relações desse movimento com o Estado, os limites são tênues, não só pela necessidade de financiamento estatal, mas também por sua presença constante no interior de agências do governo. Essa fluidez, por certo, trouxeme algumas inseguranças, já que neste caso não havia praias ou ilhas a se aportar. Além dos diferentes modos de identificação que se podia supor, deparava-me com uma rede de indivíduos dispersos em diferentes cidades. Neste sentido, a pesquisa de campo me ajudou a pensar a idéia de cultura enquanto uma relação intersubjetiva constituída entre os sujeitos. Focando o olhar na constituição das relações e da subjetividade como algo constituído entre os sujeitos e não além ou sobre eles (STRATHERN, 1996; VIVEIROS DE CASTR0, 2002). A relação no ativismo soropositivo se daria principalmente a partir da convergência de meus interlocutores à categorias comuns pelas quais passaram a organizar uma experiência partilhada (doença-ativismo).

Foi então por meio das narrativas que comecei a apreender o ativismo enquanto uma categoria coletiva estruturante das experiências individuais. Os relatos biográficos neste caso podem ser vistos eles mesmos enquanto estruturas particulares, bricolagens forjadas de eventos e temporalidades, onde as categorias do discurso nativo, tais como o ativismo, desempenham em seu conjunto o papel de uma noção que permite 0 equacionamento de realidades distintas - entre a experiência da doença ${ }^{8}$, as várias ordens de conflitos e a condição de "sujeito político"/cidadão/ativista" (OCHS; CAPPS, 1996). Logo, além da observação de como os pormenores do comportamento habitual

\footnotetext{
${ }^{8}$ A experiência da doença aparece aí relacionada como momento que possibilita um salto em relação a um novo arranjo da vida e a descoberta dos direitos de cidadania.

${ }_{9}^{9}$ Em diferentes momentos, eles falam sobre como ser ativista, e da importância do ativismo em sua vida, como as coisas mudaram depois dos treinamentos, da descoberta dos direitos.
} 
exprimem relações, minha pesquisa passou a envolver a escuta detalhada das experiências individuais e dos discursos narrativos.

Era preciso entender aí o papel que a própria idéia de ativismo, presente de modo recorrente nos discursos e nas narrativas, tinha enquanto uma categoria articuladora do saber viver com o vírus. Tratava-se portanto, de como as categorias ajudavam a dar sentido à práxis. Neste sentido, ativismo, enquanto uma categoria nativa, articulava saúde/doença e política, que como realidade vivida não podem ser pensados enquanto elementos colocados em planos distintos. Neste sentido, o ativismo conjuga modelos que no interior do pensamento ocidental moderno se encontram em domínios diferentes, o primeiro, da relação saúde doença, no domínio da biomedicina, jáo segundo no campo da ciência política. É preciso pensar portanto que estes modelos correspondem a formas de conhecimento e interpretação da realidade ligados à produção de um sujeito local, à margem das concepções hegemônicas do que representariam os processos de saúde/ doença e do modo como a política é concebida.

\section{Narrativa e Política: Algumas Impressões}

As narrativas ${ }^{10}$ foram um instrumento de pesquisa, já que, através delas foi possível entender parte do processo de articulação e apreensão de um saber local. Isso porque, pelo próprio grupo, elas seriam consideradas como processo privilegiado de apreensão do mundo e da elaboração de um conhecimento sobre este. Era através do discurso narrativo, por exemplo, que se podia pensar um modelo de incorporação e reelaboração dos saberes biomédicos e de outros saberes, que estariam na base de um conjunto de estratégias terapêuticas e da elaboração de um conhecimento local que sustentasse essas práticas (SANTOS, 2005). As narrativas, entre outros aspectos, revelam a produção de uma lógica local na manipulação dos conhecimentos médicos.

As narrativas por sua vez são encaradas a partir da perspectiva de sua estrutura como arranjo intelectual que veicula, os conceitos e categorias do pensamento nativo, mas nem por isso são vistas como distintas de uma práxis.

Era possível perceber que a "aquisição da habilidade de falar sobre sua história pessoal", encarada como um gênero narrativo, era utilizada em diferentes contextos, enquanto elemento fundamental da constituição do grupo. Os treinamentos ${ }^{11}$

\footnotetext{
${ }^{10}$ Neste trabalho a narrativa é entendida como uma bricolagem onde temporalidades e eventos se desdobram na construção da história de vida. Nessa estrutura a relação entre sentido e experiência se torna fundamental e intrínseca. A partir dessa relação o relato da história de vida tende a unir a experiência a uma linha de história e a um significado.

${ }^{11}$ os "treinamentos" são um movimento que instaura o processo de formação de um novo quadro de socialização e de expressão dos sujeitos e foram abordados em Santos (2005) enquanto rituais integrativos, de acordo com a abordagem de Houseman e Severi (1998 apud SANTOS, 2005).
} 
preconizavam a "aquisição" de tais "habilidades" e além de sua função na constituição do grupo, a narrativa é uma estratégia de negociação nas e das relações sociais (OCHS; CAPPS, 1996). Elas assumem especial relevância em eventos enunciativos chave, como os grupos de adesão ${ }^{12}$ e como os acolhimentos ${ }^{13}$.

Se a adesão e o acolhimento parecem ser momentos relevantes de enunciação, nas reuniões de ativistas e em suas participações em fóruns as narrativas pessoais exercem papel fundamental como meio pelo qual o grupo organiza, presentifica e compartilha informações e conhecimentos. Contar uma história ou um evento, geralmente ligados à biografia individual, é estratégico quando o que está em jogo são os modos de organização do grupo. A narrativa neste caso, mais do que um meio pelo qual a experiência é organizada, é um instrumento político do grupo que legitima e reafirma sua identidade. Nestes espaços a narrativa aparece como uma demarcação simbólica de si, como identidade individual e coletiva.

Quando uma ativista toma a palavra em uma plenária, sua trajetória/itinerário pessoal traça os caminhos pelos quais seu discurso procura se legitimar. Nas narrativas que ouvi, essa trajetória é problematizada pela categoria ativismo que se refere a um sujeito coletivo e também às potencialidades positivas da doença - de sua experiência e os diversos tipos de re-ordenamento que ela possibilita. 0 ativismo, enquanto categoria nativa, permite uma síntese dessa experiência e o engendramento de uma nova condição pessoal. Esse processo se dá pela incorporação de uma nova fonte de sentidos pelo sujeito. É parte significativa disso o "aprendizado" de novas informações, como o "saber ser cidadão", a incorporação de novas práticas corporais/cuidados com o corpo e de saberes científicos (VALLE, 2003).

Esses argumentos frisam que a doença enquanto acontecimento sugere uma dinâmica que tende a ser explicitada e problematizada a partir da narrativa. A adesão ao movimento de pessoas vivendo com HIV/Aids é uma experiência problematizada pelo sujeito a partir de seu itinerário pessoal. 0 discurso de meus interlocutores tende a explicitar essa proposição quando destacam a importância do treinamento e do ativismo, assinalada pela transformação pessoal. 0 próprio momento do diagnóstico sofre uma reelaboração passando por um processo de recriação e legitimação da doença que coloca em ação os modelos de explicação elaborados pelo movimento.

0 elemento decisivo para uma abordagem a partir das narrativas foi o desvio do

\footnotetext{
${ }^{12}$ Os grupos de adesão são grupos formados para dar apoio ao paciente na adesão (compliance) ao tratamento, muitas vezes conduzidos por pessoas soropositivas e realizados tanto no interior dos serviços de saúde como no interior de ONGs e de casas de apoio.

${ }^{13}$ Trata-se do momento em que a pessoa se descobre portadora do HIV e passa a ser "acolhida" por aqueles que já tiveram que enfrentar essa situação.
} 
foco das instituições para a subjetividade. Pesquisas realizadas na área temática das organizações não-governamentais e Aids traziam alguma contribuição para se pensar o problema, mas, no entanto, falta a dimensão da realidade vivida e da elaboração de modelos explicativos. Por outro lado, não se tratava de avaliar ou levantar as demandas políticas do grupo. Motivado em explorar o campo da experiência da doença e sua relação com a adesão a uma rede de ativismo, estava preocupado com as diferenças específicas produzidas pelo movimento de Aids dentro de um contexto também específico, isto é, a ênfase recaia sobre os sentidos e a produção de um sujeito singular a partir de modelos de interpretação próprios.

Colocando sobre perspectiva algumas das motivações metodológicas e temáticas que fui adotando ao longo do percurso de construção do projeto de pesquisa e das minhas incursões ao campo, deveria abrir mão de abordagens mais sociológicas a favor de um olhar mais centrífugo. Restava procurar pensar o político para além da ênfase na organização e do sentido que se tornou corrente tradicionalmente na sociologia ${ }^{14}$. Isso implica deslocar a reflexão para os aspectos particulares pelos quais os nativos pensam e vivem suas experiências, as maneiras como aí se articulam as relações de poder e conflito.

As narrativas, através da reelaboração da história de vida, sugerem um itinerário na construção de um modelo de interpretação da ocorrência da doença na biografia dos ativistas. 0 ativismo, pensado enquanto categoria nativa, é um elemento fundamental no estabelecimento deste modelo, ele remete 0 itinerário a uma mudança pessoal. Ao contrário da testagem clínica, elemento privilegiado de imputação de sentido no sistema biomédico, ser o ponto de articulação na construção da doença, ele é só mais um elemento de ordem para dirupção provocada pela doença.

A ocorrência da doença é tida como um acontecimento dispendioso e desestruturador do sujeito, e sua explicação depende de decisões de ordem pragmática, dos interesses pessoais e coletivos (SINDZINGRE, 1991, p.101). A explicação não se reduz, nem prescinde do sistema biomédico. As tensões sociais, e os interesses e estratégias individuais e coletivos, assumem um papel importante na construção destes modelos, aí, o ativismo emerge enquanto elemento que dá unidade à explicação da doença ${ }^{15}$. Se a Aids afeta os laços sociais e provoca uma ruptura na sociabilidade

\footnotetext{
${ }^{14}$ No entanto, o que não quer dizer que não haja sociólogos que abordem a questão do poder e das relações políticas a partir de uma perspectiva processual e dinâmica onde o foco esteja nas relações entre os sujeitos. A referência é mais a um modo de olhar o problema, do que um recorte disciplinar específico.

${ }^{15}$ É importante tomar nota de que a epidemia da Aids no Brasil avançou sobre os grupos marginalizados e as camadas mais pobres da população, chegou-se mesmo a falar em pauperização e feminização (PARKER; CAMARGO, 2000).
} 
0 ativismo é uma oportunidade de reconstrução da subjetividade ${ }^{16}$. É a própria situação de margem que é reelaborada a partir do ativismo, sendo importante pensar que esta marginalidade é uma condição a priori do ser infectado. 0 ativismo possibilita que esta marginalidade seja revista face aos conhecimentos incorporados e 0 aumento da capacidade de negociação dos sujeitos, tanto frente aos saberes biomédicos, como da situação social ${ }^{17}$.

\section{Considerações Finais}

Estes pontos assinalam considerações importantes para uma compreensão do ativismo soropositivo no Paraná desde uma visão centrífuga. Nesta, o ativismo deve ser tomado como uma teoria de interpretação e ação sobre o mundo que está em forte relação com elementos exteriores, como o Estado e a biomedicina, no entanto, o modelo explicativo da doença que emerge aí deve ser tomado enquanto um agenciamento particular elaborado por um sujeito singular. A produção de um sujeito em torno do ativismo pode ser entendida, em parte, a partir dos treinamentos e da articulação de uma rede, no que diz respeito a isso, as narrativas emergem enquanto veículos de sentido e instrumentos através dos quais um conhecimento nativo é produzido e articulado. Este conhecimento tem um papel fundamental no estabelecimento de um modelo nativo de interpretação da doença. 0 que se percebe nas narrativas é que a idéia de ativismo é articuladora deste modelo, colocando em relação doença e política. A situação de margem vai desempenhar um papel importante na construção deste modelo reestabelecendo novos espaços de sociabilidade ao sujeito. A alternativa à margem se constrói a medida em que o modelo se articula e a possibilidade de atuação como um ativista se torna real, supondo o ativismo, não só como teoria sobre o mundo, mas como realidade vivida.

Os modelos de interpretação do ativismo soropositivo no estado do Paraná se constituem, portanto, enquanto estratégias de deslocamento da margem. A entrada no universo desde ativismo, figura nas narrativas como uma possibilidade de articulação de uma nova sociabilidade, ou seja, a integração em novos espaços sociais. Este fator não está dado somente pela possibilidade de inserção em projetos financiados e na possibilidade de renda, mas também no reconhecimento social pela comunidade, processo reverso ao da chamada "morte social". Contudo, é preciso não ver o ativismo

\footnotetext{
${ }^{16}$ Penso esse momento como momento de emergência de um novo sujeito a partir dos laços integrativos gerados pelo ativismo.

${ }^{17}$ Essa reelaboração corresponde a criação de territórios existenciais, um espaço próprio de produção de um sujeito singular, sobre esta questão ver: Deleuze e Guattari (1995). Sobre a noção de margem empregada aqui, pode-se consultar a mesma referência.
}

Doença, Política e Subjetividade no Atrvismo Soropositivo no Paraná • 41 
somente por este aspecto, mas também a partir da própria articulação entre doença e política que é estabelecida na narrativa, associada aí à entrada em um novo mundo simbólico, a reelaboração das subjetividades.

\section{REFERÊNCIAS}

Associação Londrinense Interdisciplinar de Aids. Relatório técnico narrativo: projeto "Ativismo e Cidadania". Londrina, 2002. (mimeo)

ALVAREZ, S. E.; DAGNINO, E; ESCOBAR, A. (Org.). Cultura e política nos movimentos sociais latino-americanos: novas leituras. Belo Horizonte: UFMG, 2000.

AUGÉ, M. Ordre biologique, ordre sociale: la maladie, forme elementaire de l'evenement In: AUGÉ, M.; HERZLICH, C. (eds). Le sens du mal: anthropologie, histoire, sociologie de la maladie. 3. ed. Paris: Archives Contemporaines, 1991. (Ordres Sociaux).

BASTOS, C. Ciência, poder, acção: as repostas à SIDA. Lisboa: Imprensa de Ciências Sociais, 2002.

BOLTANSKI, L. Les Cadres. la formation d'un groupe social. Paris: Éditions de Minuit, 1982.

DELEUZE, G.; GUATTARI, F. Mil Platôs: capitalismo e esquizofrenia. Rio de Janeiro: Editora 34, 1995.

EVANS-PRITCHARD, E. E. Os nuer: uma descrição do modo de subsistencia e das instituições politicas de um povo nilota. São Paulo: Perspectiva, 1978.

GALVÃo, J. As respostas das organizações não-governamentais frente à epidemia de HIV/Aids. In: PARKER, R. G. Políticas, instituições e AIDS: enfrentando a epidemia no Brasil. Rio de Janeiro: ABIA, 1994.

Aids no Brasil: a agenda de construção de uma epidemia. Rio de Janeiro: ABIA, 2000.

GOLDMAN, M. Segmentaridades e movimento negro na Bahia. Mana, Rio de Janeiro, v. 7, n. 2 , p. 57-93, 2001.

HERZLICH, C.; PIERRET, J. Uma Doença no Espaço Público. A AIDS em Seis Jornais Franceses. PHYSIS: Revista de Saúde Coletiva, Rio de Janeiro, v. 15, supl., p. 71-101, 2005.

JEOLÁS, L. S. O jovem e o imaginário da Aids: 0 bricoleur de suas práticas e representações. 1999. Tese (Doutorado em Antropologia Social) - Pontifícia Universidade Católica de São Paulo, São Paulo.

LÉVI-STRAUSS, C. Totemismo hoje. São Paulo, Abril, 1976. 
MACCALLUM, C. Alteridade e sociabilidade Kaxinauá: perspectivas de uma antropologia da vida diária. Revista Brasileira de Ciências Sociais, São Paulo, v. 13, n. 18, p. 1998.

MALUF, S. W. Les enfants du Verseau au pays des terreiros: les cultures thérapeutiques et spirituelles alternatives au sud du Brésil. Thèse (Doctoraten Anthropologie Sociale et Ethnologie) - École des Hautes Études en Sciences Sociales, Paris, 1996.

Antropologia, narrativas e a busca de sentido. Horizontes Antropológicos, Porto Alegre, v. 5 , n. 12, p. 69-82, 1999.

PARKER, R. (Org.). A construção da solidariedade: AIDS, sexualidade e política no Brasil. Rio de Janeiro: Abia, 1994.

PARKER, R.; CAMARGO JR., K. R. Pobreza e HIV/AIDS: aspectos antropológicos e sociológicos. Cadernos de Saúde Priblica, Rio de Janeiro, v. 16, supl.1, p. 89-102, 2000.

POLLAK, M. Os bomossexuais e a AIDS: sociologia de uma epidemia. São Paulo: Estação Liberdade, 1990.

OCHS, Elionor; CAPPS, Lisa. Narrating the Self. In: ANNUAL REVIEW OF ANTHROPOLOGY, 25. 1996. p. 19-43

RIBEIRO, Gustavo Lins. Cybercultural Politics. Political activism at distance in a transnational world. Brasilia: Unb, 1996. (Série Antropologia, 212).

SANTOS, T. M. Políticas e subjetividades: itinerários do ativismo sorpositivo. 2005. Dissertação (Mestrado em Antropologia Social) - Universidade Federal de Santa Catarina, Florianópolis.

SEEGER, A:; DA MATTA, R.; VIVEIROS DE CASTRO, E. A construção da pessoa nas sociedades indígenas brasileiras. Boletim do Museu Nacional, Rio de Janeiro, n. 32, p. 2-19, maio 1979.

SINDZINGRE, N. La nécessité du sens: l'explication de l'infortune chez les Senufo. In: AUGÉ, M.; HERZLICH, C. (Eds.). Le sens du mal: anthropologie, histoire, sociologie de la maladie. 3. ed. Paris: Archives Contemporaines, 1991. (Ordres Sociaux).

STRATHERN, M. The gender of the gift: problems with women and problems with society in Melanesia. Berkley: University of California, 1988.

For the motion (1). In: INGOLD, T. (Ed.). Key debates in anthropology. London: Routledge, 1996.

VALLE, C. G. 0. do. Sintomas, exames e medicamentos: doença e corpo no caso da epidemia de HIV/Aids. In: ENCONTRO ANUAL DA ANPOCS, 27., 2003, Caxambu. Anais... Caxambu, 2003. VIVEIROS DE CASTRO, Eduardo. 0 conceito de sociedade em antropologia. In: . A Inconstância da Alma Selvagem: e outros ensaios de antropologia. São Paulo: Cosac e Naify, 2002. 